\title{
Relation Between SF-36, mHAQ Scores and Disease Activity in Rheumatoid Arthritis
}

\author{
Aya MG ${ }^{1}$, Nihal A.F. ${ }^{2}$, Nagwa S.Ahmad ${ }^{3}$ Mohammed AI, \\ 1. Specialist of Rheumatology and Rehabilitation Faculty of Medicine .Assiut University \\ 2. Professor of Rheumatology and Rehabilitation Faculty of Medicine .Assiut University, \\ 3. Professor of Biochemistry, Faculty of Medicine, Sohag University, \\ 4. Assistant Professor of Rheumatology and Rehabilitation Faculty of Medicine Sohag,
}

\section{Abstract}

Objective: To investigate the relationship between quality of life (QOL) and disease activity in patients with rheumatoid arthritis (RA).

Methods: 200 patients with RA were included in the study. Data were obtained by questionnaires and laboratory investigation. Disease Activity Score (DAS-28) was calculated for assessment of disease activity. Separate dimensions and physical and mental summary scores of the Short form Health survey (SF-36) and Health Assessment Questionnaire (HAQ) were compared to study the relationship between QOL and disease activity in patients with rheumatoid arthritis.

Results: There was a significant association between DAS-28 and QOL scores.

Conclusions: RA has a significant effect on the health related quality of life of patients, and its activity is ditectly related to worse QOL.

Keywords: Rheumatoid arthritis, Quality of life, DAS-28, SF-36.

\section{Introduction}

Rheumatoid arthritis (RA) is a chronic, multi-systemic autoimmune and inflammatory disease, which can result in significant functional disability and depressive symptoms. These changes may have a negative influence on the performance of daily living and work activities, with consequent impact on the quality of life (QOL) ${ }^{(\mathbf{1})}$.

The RA activity and the degree of joint damage are critical in the evolution of the dysfunction. They had been measured by objective instruments, like the disease activity score for 28 joints (DAS-28) ${ }^{(2)}$. The ACR criteria measure the difference between two evaluation moments in a patient using joint assessment, patient and physician global assessment, the health assessment questionnaire (HAQ) ${ }^{(\mathbf{3})}$.

Moreover, the Disease-specific instrument included to measure functional limitations, the HAQ in RA was closely correlated to the physical functioning dimension of the 36-item short form (36-SF) health survey, therefore SF-36 is considered a valid instrument for measuring physical functioning and comparing different aspects of HRQoL in patients with $\mathrm{RA}^{(4)}$.

\section{Aim of the work:}

The aim of this work was to investigate the relationship between quality of life (QOL) and disease activity in patients with rheumatoid arthritis (RA).

\section{Patients and Methods:}

This study was carried on 200 rheumatoid arthritis patients fulfilled the 2010 new classification criteria $^{(5)}$. The patients were recruited from the Rheumatoiology and Rehabilitation outpatient and inpatient clinics at Sohag and Assiut University Hospitals. The Ethical committee of both University Hospitals approve the design of this study. 
Methods:

It is a cross sectional study. All patients performed laboratory investigations and underwent a medical examination by a single rheumatologist who also determined the disease duration and assessed the disease activity score in 28-joints (DAS-28). Patients were classified as in remission (<2.6), low $(2.6-<3.2)$, moderate $(3.2$ - 5.1), and high (>5.1) disease activity. HRQoL was measured via the Medical
Outcomes Study 36-SF health survey and Health Assessment Quesionnaire (HAQ) scores.

\section{Statistical analysis:}

Date entry and data analysis were done using SPSS version 23 (Statistical Package for Social Science). Data were presented as number, percentage, mean, standard deviation. ANOVA was used to compare means among gfroups. P-value was considered statistically significant when $\mathrm{P}<0.05$.

\section{Results}

This study included 200 patients with rheumatoid arthritis fulfilled 2010 ACR/EULAR classification criteria.

Table (1) shows demographic and clinical data in the study control group.

Table (2) shows comparison of HAQ and SF-36 according disease activity in the study group, with significance difference $(\mathrm{P}<0.05)$.

Table (1): Demographic data in study \& control groups.

\begin{tabular}{|l|c|}
\hline Item & $\begin{array}{c}\text { Study group } \\
\text { "n=200" }\end{array}$ \\
\hline 1- Age “years" & $43.68 \pm 9.35$ \\
2- Sex (Male:Female) & $20: 180$ \\
3- Marital status & \\
• Single & $24(12.0 \%)$ \\
- Married & $176(88.0 \%)$ \\
\hline 4- Clinical Data & \\
\hline • Arthralgia & $172(86.0 \%)$ \\
- Swelling & $170(70.0 \%)$ \\
- Deformity & $44(22.0 \%)$ \\
- Constitutionals symptoms & $96(48.0 \%)$ \\
- Extra. Art. manifestations & $1.79 \pm 0.96$ \\
- D.M & $4(2.0 \%)$ \\
- Disease duration “years" & $1.79 \pm 0.96$ \\
- Morning Stiffness "minutes" & $27.0 \pm 5.87$ \\
\hline 5- Disease activity (DAS28-ESR) & \\
\hline • Low & $55(27.5 \%)$ \\
- Moderate & $80(40.0 \%)$ \\
- High & $65(32.5 \%)$ \\
\hline
\end{tabular}

Table (2): Comparison of rheumatoid factor "RF", Anti - CCP , HAQ and SF36 data according disease activity in study group.

\begin{tabular}{|l|c|c|c|c|}
\hline Item & Mild "n=55" & Moderate "n=80" & High "n=65" & p-value \\
\hline HAQ & $1.02 \pm 0.02$ & $1.75 \pm 0.05$ & $3.22 \pm 1.38$ & $\mathrm{P}<0.001^{* *}$ \\
\hline SF-36 & $86.67 \pm 4.56$ & $74.23 \pm 2.45$ & $45.62 \pm 2.57$ & $\mathrm{P}<0.001^{* *}$ \\
\hline
\end{tabular}




\section{Discussion}

Rheumatoid arthritis (RA) is a chronic inflammatory polyarthritis with a prevalence of $0.5 \%$ to $1 \%$ in the general population. ${ }^{-}$It has been accepted that initiating RA treatment at the early stage of disease improves clinical outcomes and prevents further joint destruction ${ }^{(5)}$.

Because of the variable expressions of RA, different indices have been defined to evaluate the disease activity and response to treatment, for instance, Disease Activity Score in 28 Joints (DAS28) and Clinical Disease Activity Index (CDAI) ${ }^{(6)}$.

In present study there were highly significance difference between disease activity and both of SF36 and HAQ.

Our findings are in agreement with other study from India, Patients with RA were found to have greater reduction in QOL than those without Ex. RA $^{(7) \text {. }}$

We therefore conclude that the SF-36 is a valid instrument for measuring physical functioning and comparing different aspects of health related QOL in patients with RA. Moreover the SF36 captures a wider range of disability in RA, in which comorbidity may also have an important role.

\section{References}

1. Anna Paula Ribeiro Campos; Cinthia Maria Silva; Shamyr Sulyvam de Castro; Cristiane Vitaliano Graminha, Depression and quality of life in rheumatoid arthritis individuals and stable health individuals: a comparative study. Fisioter. Pesqui. 2013;20(4).

2. Cader MZ, Filer A, Hazlehurst J, et al. Performance of the 2010 ACR/EULAR criteria for rheumatoid arthritis: comparison with 1987 ACR criteria in a very early synovitis cohort Ann Rheum Dis 2011; 70:949-55.

3. Weinblatt ME, Keystone EC, Furst DE, Kavanaugh AF, Chartash EK, Segurado OG. Long term efficacy and safety of adalimumab plus methotrexate in patients with rheumatoid arthritis: ARMADA 4 year extended study. Ann Rheum Dis 2006;65:753-9.

4. Costa AFC, Brasil MAA, Papi JA, Azevedo MNL. Depressão, ansiedade e atividade de doençan aartrite rheumatoid. Rev Bras Reumatol. 2008;48(1):7-11.

5. Aletaha D, Neogi T, Silman AJ, et al. 2010 rheumatoid arthritis classification criteria: an American College of Rheumatology/ Euro-pean League Against Rheumatism collaborative initiative. Ann Rheum Dis. 2010;69:1580-1588.

6. Castrejón1, A.M. Ortiz1, R. GarcíaVicuña1, J.P. Lopez-Bote1, A. Humbría1, L. Carmona2, I. GonzalezAlvaro1 sedimentation rate equivalent when estimating the 28-jointdisease activity score in rheumatoid arthritis? Clinical and Experimental Rheumatology 2008; 26: 769-775.

7. Haroon N, Aggarwal A, Lawrence A et al. Impact of rheumatoid arthritis on quality of life. Mod Rheumatol. 2007;17:290-5. 